\title{
Training for Tourism Companies Staff Against Human Trafficking
}

\author{
Lucia Varra, Ilaria Prisco \\ University of Florence, Florence, Italy
}

Human trafficking, involving mostly women and children, is closely related to the tourism businesses, because traffickers use often through their complicity, which including various companies: airports, trains, hotels, etc.. This work $^{1}$ aims to analyze the effectiveness of training as a tool for monitoring and preventing this crime. After data and information collecting on the issue of human trafficking and links with the tourism industry, we analyzed the main training toolkits provided by organizations which deal with the prevention and monitoring of this phenomenon, two questionnaires were built and sent: the first questionnaire was sent to 136 organizations that are training for the staff of tourism companies; it aims to detect the educational needs that the organizations want to satisfy, the educational target, teaching techniques, and the results obtained with the training; the second questionnaire was sent to 495 companies who participating in the courses, explores the motivations, the educational objectives, and results related to the training received. Through this work, the authors only present the first results obtained during the first phase, involving the point of view of seven organizations offering training courses. The answers provided by the companies show that the learning targets have been fully achieved, in particular with regard to raising awareness on the issue. Still, some gaps with regard to the support that the training may offer in the development of new attitudes and skills to prevent and monitor the phenomenon. The course contents and teaching techniques used appear to be consistent with the objectives. All of the organizations interviewed carried out the evaluation of the course learning demonstrate how companies training participants are satisfied with the results, especially in terms of knowledge and skills to contribute to the prevention of an increasing phenomenon, while less significant are the advantages about the decrease of concrete human trafficking situations.

Keywords: human trafficking, social development, staff training, sustainable tourism

\section{Introduction: Trafficking in Human Beings and the Links Within Tourism Industry}

Trafficking in human beings is a worldwide trade whose purpose is to exploit men, women, and children. Specifically, according to the definition of United Nations, taken by UNODC (United Nations Office on Drugs

\footnotetext{
Lucia Varra, Researcher of Organization Behavior, Department of Business Administration, University of Florence. Ilaria Prisco, Bachelor's degree in Economics and Business of Tourism Industry, University of Florence.

Correspondence concerning this article should be addressed to Lucia Varra, Department of Business Administration, Via delle Pandette 9, 50127, Firenze, Italia. E-mail: lucia.varra@hotmail.com.

${ }^{1}$ This work is a wider research project which has been carrying out since 2011 by Ray Nolan (Sheffield Hallam University, project manager of the research project) and in which Ilaria Prisco has taken part. However, the methodology and the questionnaires used here are made by the authors of this paper.
} 
and Crime), it is (UNODC, 2004, Art. 3, pp. 42-43):

...the recruitment, transportation, transfer, harbouring or receipt of persons, by means of the threat or use of force or other forms of coercion, of abduction, of fraud, of deception, of the abuse of power or of a position of vulnerability or of the giving or receiving of payments or benefits to achieve the consent of a person having control over another person, for the purpose of exploitation...

The Trafficking Protocol is one of three Protocols adopted within the Convention against Transnational Organized Crime that came into force on December 25, 2003. By on June 2010 it had been ratified by 117 countries and 137 parties. However, particularly in Africa, there are still several countries where there is a lack of necessary legal instruments.

As regards the purposes of human trafficking, the most commonly identified form is sexual exploitation (79\%), followed by forced labour (18\%). The remaining part (3\%) represents other types of exploitation (UNODC, UN.GIFT, 2009, p. 6).

In general, exploitation may take one of the following three forms: sex trafficking, which may consist of exploiting prostitution of other people or other form of sexual exploitation, such as pornography, sexually-oriented performances, and sex tourism; trafficking for non-commercial sex purposes, which may include early marriage, forced or servile marriage, arranged marriage, compensation marriage, transactional marriage, temporary marriage, or marriage for childbearing; labour trafficking, which may involve domestic servitude, sweatshop, agricultural or construction labour, or enforced enrolment in an armed force (UNODC, UN.GIFT, Inter-Parliamentary Union, 2009, pp. 14-15). At a global level, the minimum number of trafficked people for forced labour (sexual exploitation included) is 2.5 million people (UNODC, UN.GIFT, 2008a, p. 6). Concerning the profile of the victims, from 2003 to 2006, 80\%-84\% is represented by female victims (women and girls), while children represent $13 \%-21 \%$, and male represent about $16 \%-21 \%$ of the total of the victims detected (UN.GIFT, 2009, p. 17).

The phenomenon of trafficking in human beings affects every country of the world with reference to the phase of the trafficking process, as origin country, transit country, or destination country, or even their combination. Human trafficking exists in less developed countries as well as more developed ones, where people are attracted by traffickers who use their difficult economic, social and political situation to convince them to leave. Mostly, trafficking in human beings is national or regional phenomenon, but there are also notable cases of long-distance trafficking. Europe is the destination for victims from the widest range of destinations while victims from Asia are trafficked to the widest range of destinations. The Americas are prominent both as the origin and destination of victims of human trafficking (UN.GIFT, 2010, pp. 15-20).

As regards the type of industries involved in this phenomenon, trafficked forced labours are usually people who working on the fringes of the formal economy, with irregular employment or migration status. The sectors mostly provide them a job are agriculture or horticulture, construction, garments, and textiles under sweatshop conditions, catering and restaurants, domestic work, entertainment, and the sex industry. The exploitation of trafficked people is also closely connected with the tourism industry such as transport sector (airports, seaports, and railways), accommodation sector (hotels, owners, and landlords of apartments), intermediaries (travel agencies) and leisure and entertainment activities. They are some of common facilitators which represent a key component of trafficking operations and make such crimes possible (Smith \& Healy Vardaman, 2010-2011, pp. 
288-291). Transport is obviously involved in the entire trafficking process: victims are sent from their origin country to the country of destination through the transit country by air, sea, or land and this happens by making use of legal businesses such as airlines, car rental, trucks, cruise lines, and railways. Accommodation facilities may be mostly involved in the third phase of the process and they are considered as a place which gives, for example, jobs to the trafficked victims or used for sexual exploitation. In France, for example, 15\% of victims of forced labour is exploited by hotel, bar, and catering sector (UNODC, UN.GIFT, 2009b, pp. 20-22). Traffickers and trafficking networks also rely on the complicity of legitimate local businesses like travel agencies, when before leaving a country with the victim. Therefore, trafficking may be supported, promoted, or facilitated consciously or unconsciously by travel agency employees who sometimes may also benefit from the trafficking and procuring activity (Viuhko, 2010, pp. 68-70). Although national and international security organizations and institutions focus their attention on this issue, human trafficking seems to be hardly foreseeable and verifiable with the exclusive involvement of the law enforcement agencies. The missing link of the prevention and monitoring process seems to be the capacity of the tourism organizations both in catching the weak signals of potential criminal situations and in creating effective responses to control the problem (GAATW, 2008).

This paper is made by the following sections: section one is "Introduction: Trafficking in Human Beings and the Links within Tourism Industry"; section two is "Tools for prevention and control: role of training”; section there is "The survey: methodology and first results" which also includes "Presentation of the organizations involved in the survey" and "Research Results" part; the last section is "Conclusion".

\section{Tools for Prevention and Control: Role of Training}

The article 9 of the Trafficking Protocol (UNODC, 2004, pp. 45-46) defines "prevention” with basic principles such as inclusion, empowerment and risk reduction, and recommends action for State parties in areas of prevention. State parties "shall establish comprehensive policies, programmes and other measure to prevent and combat trafficking in persons and to protect victims of trafficking in persons, especially women and children, from revictimization” (UNODC, 2004, pp. 45-46). The above mentioned article gives importance to measures like research, information, campaigns as well as economic activities to combat trafficking and raise people's awareness. The Protocol recognises the fundamental role of the state that can drive change, with the help of non-governmental organizations and other relevant organizations and other elements of the civil society, and through its social protection and law enforcement policies, it may both prevent criminal activities and empower vulnerable populations.

Organization for Security and Co-operation in Europe (OSCE) member states recognised three necessary areas to the development of prevention activities of which details are given in the OSCE Action Plan to Combat Trafficking in Human Being. The first area is the prevention of the phenomenon through the development of public awareness and education to face the need to inform the public, potential victims also included, about the importance and the dangers of trafficking in people. The second area of prevention is identified in that kind of prevention which makes use of data collection and research in order to understand both the aim as well as the nature of trafficking within those countries. Finally, the third form of prevention is the one that includes the development of economic and social interventions regarding human trafficking which reflect the necessity to create helpful alternatives for the potential victims (UNODC, UN.GIFT, 2008b, pp. 62-63). 
Moreover, the United Nations are aware of that trafficking can be prevented by both within the area of origin as well as the area of transit and of the destination. The efforts of prevention in the area from which victims are trafficked are awareness-raising, promotion of income-generating activities, including microcredit, job creation, and career advice; other efforts may be focus and non-focus on education and targeting groups of people at high risk of being trafficked. As regards prevention within the transit area, border points have a key role in intercepting people who are being trafficked within the places where exploitation occurs, several States have invested money in employment laws concerning migrant workers and regulation of recruitment.

Prevention activities have to be evaluated and monitored. The importance of monitoring the effectiveness of prevention techniques and interventions is subsequent to accurate research and data collection phase on all forms of trafficking. Research and data collection are necessary to ensure adequate prevention, protection and assistance to trafficked people and the prosecution of traffickers and they are vital to monitor, evaluate, and assess the impact of prevention. With reference to the Trafficking Protocol, the article 6 (UNODC, 2004, pp. 43-44) concerns the assistance and the protection of the trafficked victims and introduces the aspect of training. Besides protecting the privacy and identifying the victims, ensuring information and assistance through legal or administrative system, providing the recovery, the physical safety and employment with the cooperation of non-governmental organizations and civil society and ensuring the possibility of obtaining compensation for damage suffered, each State Party shall also provide “training opportunities” (UNODC, 2004, pp. 43-44). Moreover, the article 10 of Protocol (UNODC, 2004, pp. 46-47) underlines that State parties shall provide training for law enforcement, immigration and other relevant officials in preventing human trafficking and it should focus on methods used to prevent the phenomenon, by prosecuting the traffickers and protecting the victims' rights and providing them safety from the traffickers. Training should also promote cooperation with non-governmental organizations, other relevant organizations, and elements of civil society (UNODC, 2004, pp. 46-47).

UNODC has developed a model law in efforts to give assistance to member States in fighting against human trafficking and to assist them in implementing the provisions contained in the Trafficking in Persons Protocol. The Model Law against Trafficking in Persons is adaptable to the needs of each State, despite the different legal traditions and social, economic, cultural, and geographical conditions of that State. The model affirms that the State shall recognize the necessity of training for families, local communities and governmental and civil society institutions to fulfil their responsibilities in the prevention of human trafficking and in law enforcement. The document advises to establish national victims funds to which trafficked people can apply for their compensation for damages suffered, and then, gives some examples of detailed provisions for the management of the funds such as training for victims of trafficking in persons and training and capacity-building connected with the protection, assistance and reintegration of victims. The document also establishes a National Anti-Trafficking Coordinating Body which shall carry out the development of a national plan of action, and this plan includes a set of measures for prevention of trafficking among which there is the training of relevant state and non-state agencies. The model states the necessity of cooperation between agencies in sharing and exchanging information and participating in training programmes. Moreover, it encourages States to design training programmes and “... involve all relevant State and non-State agencies, including law enforcement, immigration, labour and other relevant officials, judicial officers, legal services, health-care and social workers, local service providers and other relevant 
professionals and civil society partners..." (UNODC, UN.GIFT, 2009c, p. 89) for their education on human trafficking, its legislation and victims' rights, their empowerment on the identification of victims, assistance and protection, and finally for the promotion of multidisciplinary and multi-agency cooperation.

As regards the involvement of the travel and tourism sector, UN.GIFT recognizes the importance of the role of the sector for the prevention and monitoring of human trafficking. Therefore, UN.GIFT is working with companies worldwide, in particular, airlines, hotels, bus, and rail lines identifying policy measures and corporate strategies for the prevention of the phenomenon; it also promotes good Corporate Responsibility (CSR) measures, supports knowledge networks and offers a database of good practices for companies. Currently, UN.GIFT is implementing awareness raising campaigns with Qatar Airways, South African Airways, Hilton Hotel Vienna, Euro lines, and OEBB. Following the World Congress I against sexual Exploitation of Children, which was held in Stockholm in 1996 (Retrieved from http://www.csecworldcongress.org/en/stockholm/index.htm), the travel and tourism sector was asked to cooperate and fight against human trafficking.

According to UN.GIFT, the global tourism industry, with UNICEF and ECPAT International (End Child Prostitution, Child Pornography and Trafficking of Children for Sexual Purposes), has given positive responses and undertaken significant initiatives for the protection, in particular of children, from sexual exploitation and trafficking for commercial sexual exploitation in travel and tourism industry. One of the most developed voluntary systems for the prevention of the phenomenon is the Code of Conduct for the Protection of Children from Sexual Exploitation in Travel and Tourism (UN.GIFT, 2010, pp. 15-50). The Code was initiated in April 1998 by ECPAT Sweden in cooperation with Scandinavian tour operators and the World Tourism Organization (WTO). In 2003, the Code was recognized by British Airways with Tourism for Tomorrow Award in the category of large-scale tourism; in 2007, the Code received the Ashoka Changemakers and Humanity United Ending Global Slavery Award, and finally, in 2010, the collaboration between the Code and Carlson won the 2010 Ethical Corporation Award. The Code of Conduct bases on six criteria, which may be implemented by the signatories of the Code, included the one which aims "to train the personnel in the country of origin and travel destinations” (criterion No. 2, ECPAT, 1998). The Code has been signed by tour operators, hotels, travel agents, organizations, and airlines. Currently, company signatories number is over 1,000 companies in 42 countries across Europe, Asia, Africa, and the Americas including major global brands such as Kuoni Holding, Accor Hotels, DRV Germany, SKÅL International, Sun n Sand Kenya. Some examples of good practice by travel and tourism leaders are the ones of ACCOR which has been involved since 2002 in large number of initiatives to eliminate the sexual exploitation of children. In 2009, the company trained 13,000 employees and displayed ECPAT campaign materials in its hotels to raise awareness amongst guests. Carlson, the first major North American company which signed the Code in 2004, has created a training kit for staff for assessing and recognizing potential situation of sexual exploitation of children, including a Manager's Guide as well as visual presentations of seven real-life scenarios that hotel personnel might encounter (UN.GIFT, 2010, pp. 15-50).

\section{The Survey: Methodology and First Results}

The survey has the purpose of examining the role of training in prevention of trafficking phenomenon, following this goal, a more extensive research has been structured. The global research project, which is still at the first phase, aims to detect both the organizations' point of view which delivers training, and the ones of tourism 
companies which has been trained over the last few years. The most important and active supplier organizations have been contacted, and 136 questionnaires have been sent. The questionnaire aims to understand the educational needs that the organizations want to satisfy, the educational target, teaching techniques, and the results obtained with the training. A sample of 495 tourism companies which may participate in the training has been identified and a questionnaire has been sent to them. The questionnaire investigates the main reasons why the companies have participated in training courses (increase of concrete human trafficking situations within the company, law awareness/knowledge of the issue, etc.), the educational objectives and results that have been reached.

Therefore, the methodology of the entire research project includes:

- data collection and analysis about human trafficking issue and the links with the tourism industry;

- analysis of the main training tool kits provided by organizations which deal with the prevention and monitoring of the phenomenon;

- analysis of the questionnaires: one completed by the main suppliers of training kits and the other one completed by tourism companies which have trained their own staff.

Through this work, the authors introduce the first results collected during the first phase concerning the organizations' point of view which provide training courses, and the first results are about seven international organizations with bases in different countries, which helped us to make some first considerations about the role of training. In some cases, the questionnaires have been completed by more than one base belonging to the same organization.

\section{Presentation of the Organizations Involved in the Survey}

The results that we are presenting refer to the following international organizations, some of them provided us more than one questionnaires, completed in the different operative bases:

ABTA (The Association of British Travel Agents) founded in 1950, is the UK's biggest travel trade association with the aim of helping Members to grow their businesses successfully and sustainably, and to help their customers to have confidence in their travel experience (http://www.abta.com/home). ABTA works closely with governments, destinations and health and safety experts to safeguard tourists and locals. ABTA has developed practical tools to implement sustainability initiatives such as training for hoteliers and service providers. In 2009, ECPAT UK and ABTA have launched”- a free e-learning course on child protection for the travel industry.

TAT (Truckers Against Trafficking) is an American website created in 2009 for members of the trucking/travel plaza industry as well as other travellers to learn how to help stopping trafficking (http://www.truckersagainsttrafficking.com). The goal of Truckers Against Trafficking (TAT) is to educate, equip, empower and mobilize members of the trucking and travel plaza industry to combat domestic sex trafficking through the normal course of their jobs. Another goal of TAT is to provide training to orientate all truck stop and travel plaza employees, all students of private and public trucking driving schools, all truck drivers employed via major carriers or owners/operators.

UN.GIFT (Global Initiative to Fight Human Trafficking) was launched in March 2007 to promote the global fight on human trafficking, on the basis of international agreements reached at the UN. The Global Initiative is based on the principle that human trafficking is a crime of such magnitude and atrocity that has to be dealt with a 
global involvement that means a global, multi-stakeholder strategy that builds on national efforts throughout the world (http://www.ungift.org/knowledgehub). The main goals of Global Initiative are to foster awareness, global commitment and action to counter human trafficking in partnership with different stakeholders including governments, the international community, non-governmental organizations and other elements of civil society and the media and to assist countries in creating and strengthening support structures for victims of trafficking.

UNICRI (United Nations Interregional Crime and Justice Research Institute) was established in 1968 by the Economic and Social Council (ECOSOC) following Resolution 1086 which urged an expansion of United Nations activity in crime prevention and criminal justice. The Institute carries out action-oriented research, training, and implements technical cooperation programmes. It aims to assist governments and the international community in tackling the threats that crime poses to social peace, development, and political stability and in fostering the development of right and efficient criminal justice systems (http://www.unicri.it).

HTAP (Human Trafficking Awareness Partnerships) is an American organization founded in 2006 with the purpose of spreading awareness of the crime of human trafficking and bringing the issue to the forefront of public consciousness through local community action and the sharing of resources and programs among communities and organizations (http://humantraffickingawareness.com/). The HTAP tries to reach its goals by the empowerment of individual communities through education, training, and the coordination of resources, the creation of partnerships of informed communities to share information, experiences, programs and best practices and the support of research.

ECPAT (End Child Prostitution, Child Pornography and Trafficking of Children for Sexual Purposes) was established in 1990 as a three-year campaign focusing on ending the "commercial" aspect of sexual exploitation of children. It is a global network of organizations and individuals and became a global non-governmental organisation (NGO) in 1996 and a network because of its strong growth all over the world. ECPAT bases its works on the principles of the Stockholm Agenda for Action against the commercial sexual exploitation of children (CSEC). ECPAT basically publishes the results of government's activities against CSEC, explores and shares good models and experiences for prevention, develops training modules for caregivers and creates learning tools for police training curricula. Furthermore, it helps groups who are trying to make a national plan for their country or implement an existing plan providing information and advice, carries out research, develops research methodologies and promotes the participation of young people in seeking solutions to the problems and in providing support to the victims (http://ecpat.net/EI/index.asp). As previously mentioned, one of the most significant initiatives undertaken by ECPAT was the creation of the Code of Conduct for the Protection of Children from Sexual Exploitation in Travel and Tourism in 1998 to increase the protection of children within the tourism sector by implementing measures against child trafficking at a global level. Originally an ECPAT project, today, the Code is an independent organization funded by the Japan Committee for UNICEF and supported by the World Tourism Organization, and technically supported by many ECPAT groups around the world. It is considered the most efficient industry tool to combat child sex tourism with more than 1,000 members all over the world (UN.GIFT, 2010, pp. 15-60).

\section{Research Results}

Almost all the organizations that completed the questionnaire have been carrying out activities about human 
trafficking less than five years, only one of them more than five years; the others have been involved in this activity since a shorter period. They almost carry out all the educational activities in the UK and only two of them in the US. The main reason which made them providing this type of training is the knowledge of the numbers and the significance of the phenomenon but for the half of the examined cases, the initiative comes from client companies or non-profit organizations which address themselves to the trainer. In some cases, the motivation comes from the objective of getting a niche population actively combating domestic sex trafficking or from a specific fund provided by ECPAT to push a strong message out to the travel sector in the UK.

The companies which participate in the training courses mainly belong to the tertiary sector. A percentage of them (20\%) are tourism companies, usually hotels (70\%), restaurants (20\%) and the remaining part composed by other companies of tourism industry.

According to the organizations involved in the survey, the main reason that induces companies to take part in training courses about this issue concerns the "awareness/knowledge of the company about the connection between tourism companies and human trafficking", even though the "will to prevent an increasing phenomenon, even though it did not closely involved the company which wants to participate” has been arising. In some cases, although concrete human trafficking situations do not happen within the companies, the reason comes from situations that may occur for example “...at truck stops and rest stops along our nation's highways where drivers for those companies park and take place”. Another reason to participate in the training courses may come from the awareness of the necessity of a direct involvement because "Laws that punish companies not taking any measurement to prevent HT and/or mitigate the risk".

The questionnaire also detected the educational objectives that the organizations interviewed aim to reach and how much/at which level they have been reached. The following figure highlights the gaps between the prearranged level of objectives and the one actually achieved (see Figure 1).



Figure 1. Gaps between the prearranged educational objectives and the achieved one (medium value on a scale from 1 to 6 ). 
The answers, provided on a scale from 1 to 6 , highlight that the educational objectives have been fully reached, in particular, regarding the first aim they planned to achieve, that is the "development of information and general knowledge about the issue". Although they are not very significant, the gaps appear in the "development of competences to prevent and monitor the phenomenon through the acquisition of techniques and tools" and of "new attitudes and behaviours towards this issue". Coherently with the objectives that the organizations intend to reach, the contents of the courses concern legal aspects (for all the examined cases), followed by the cultural aspects and the education about prevention/monitoring tools and techniques.

The teaching technique essentially used is the focus group, the front lessons/lectures represent about the $20 \%$ of the course.

All the organizations interviewed carry out the evaluation of the educational courses results. The advantages of the training evaluation for the organizations are (in order of importance): "improvement of the skills to plan the course" and "development of the contents of the course" (medium value equivalent to 5 on a scale from 1 to 6 ); the advantages of the "knowledge of the formative needs" of the participant companies and of their specific "issue of human trafficking found"; afterwards (medium value equivalent to 4 and 4.3). The minor advantage is in terms of a "higher collaboration between educational provider and the participant companies", which may be the only real lever to create partnerships and which may strengthen the efforts of the single organization.

With reference to the obtained results by the participant companies, according to the organizations interviewed, the objectives of the single companies have been reached. Above all, the organizations think that the object concerning the "higher awareness/knowledge of the company about the connection between tourism companies and human trafficking” has been achieved (the medium value equivalent to 4.75 on a scale from 1 to 6); they also give a good value to the "skills to contribute to the prevention of an increasing phenomenon, even though it did not closely involve the participant company" (medium value equivalent to 4.66 on a scale from 1 to 6). Less significant are the advantages in terms of "decrease of concrete human trafficking situations that happen within the companies" and "decrease of staff difficulties, facing trafficking in human being situations”. Both the results have the medium value equivalent to 3.66 .

\section{Conclusions}

The link between tourism and human traffic is growing increasingly not so much because of the lack of regulatory instruments which punish the attendant crimes (even if the offenses and penalties are not completely uniform across the different countries) because of the cultural and informative problems connected with this phenomenon. There is a lack of an exhaustive knowledge of the problem which seems to relate to the "others" without understanding that the phenomenon is much more widespread and detailed than we could think. International organizations are undertaking effective activities in order to prevent the human traffic which mostly needs new attitudes and new skills. The training is the main tool to prevent and monitor this phenomenon. This survey has highlighted the strong motivation of these organizations to help make people aware of the issue and to spread knowledge as well as adequate skills. Unfortunately, many tourist businesses do not still understand the gravity of the problem and the fact that, in this research, those who participate in courses have some difficulties in filling out the questionnaires. This suggests that it still deals with a niche of users and their participation does not necessarily correspond to an active involvement in this direction. The commitment of the organizations is 
encouraging but only a stronger partnership with the tourist businesses will turn into a real tool kit available for the specific needs of the enterprise. Only in this way, the tourist business will be able to identify and solve promptly the problems related to sexual exploitation and human traffic.

\section{References}

ECPAT (1998). The code of conduct. Retrieved from http://www.thecode.org/

GAATW (2008). Europe: An overview of recent developments, bangkok. Alliance News (p. 30). Retrieved from http://www.gaatw.org/publications/Alliance\%20News/Alliance_New_Dec_2008_final.pdf

Lebov, K. (2010). Human trafficking in Scotland. European Journal of Criminology, 7(1), 77-94.

Smith, L., \& Healy Vardaman, S. (2010-2011). A legislative framework for combating domestic minor sex trafficking. Regent University Law Review, 23(2), 265-296.

Surtees, R. (2008). Traffickers and trafficking in southern and eastern Europe. European Journal of Criminology, 5(1),39-69.

UN.GIFT (2009). Progress report, Wien. $\quad$ Retrieved http://www.ungift.org/docs/ungift/pdf/about/UNGIFT_progress_report09.pdf

UN.GIFT (2010). Human trafficking and business: Good practices to prevent and combat human trafficking, Wien. Retrieved from http://www.ilo.org/wcmsp5/groups/public/---ed_norm/---declaration/documents/publication/wcms_142722.pdf

UNODC (2004). Convention against transnational organized crime and the protocols thereto (41-51), New York. Retrieved from http://www.unodc.org/documents/treaties/UNTOC/Publications/TOC\%20Convention/TOCebook-e.pdf

UNODC, UN.GIFT (2008a). Human trafficking: An overview, New York. Retrieved from http://www.ungift.org/docs/ungift/pdf/knowledge/ebook.pdf

UNODC, UN.GIFT (2008b). An introduction to human trafficking: Vulnerability, impact and action, Wien. Retrieved from http://www.unodc.org/documents/human-trafficking/An_Introduction_to_Human_Trafficking_-_Background_Paper.pdf

UNODC, UN.GIFT (2009a). Global report on trafficking in persons, Wien. Retrieved from http://www.unodc.org/documents/Global_Report_on_TIP.pdf

UNODC, UN.GIFT (2009b). Trafficking in persons: Analysis on Europe, Wien. Retrieved from http://www.unodc.org/documents/human-trafficking/Trafficking_in_Persons_in_Europe_09.pdf

UNODC, UN.GIFT (2009c). Model law against trafficking in persons, Wien. Retrieved from http://www.unodc.org/documents/human-trafficking/Model_Law_against_TIP.pdf

UNODC, UN.GIFT, Inte-Parliamentary Union. (2009). Combating trafficking in persons. A Handbook for Parliamentarians (p. 16), Wien. Retrieved from http://www.unodc.org/documents/human-trafficking/UN_Handbook_engl_core_low.pdf

Viuhko, M. (2010). Human trafficking for sexual exploitation and organized procuring in Finland. European Journal of Criminology, 7(1), 61-75.

Wopschall, P. K. (2011). Human trafficking in San Luis Obispo county: Assessing the local law enforcement's mechanism for prevention. Retrieved from http://digitalcommons.calpoly.edu/cgi/viewcontent.cgi?article=1047\&context=socssp\&sei-redir=1\&referer=http\%3A $\% 2 F \% 2$ $\mathrm{F}$ 